\title{
Smart Medicine Time Indication Box
}

\author{
Suneetha Uppala ${ }^{1}$, B. Rama Murthy ${ }^{2}$ \\ ${ }^{1}$ Department of Electronics, S. K. University, Anantapur, A.P \\ ${ }^{2}$ Professor, Department of Instrumentation, S. K. University, Anantapur, A.P
}

\begin{abstract}
In the present paper describe how to build a microcontroller based smart medicine time indication box. This medicine box is help for user who regularly take drugs or supplements and also nurses who take care of the older or patients. The medicine box is programmable that allows nurses or users to specify the pill quantity and day to take pills, and the serve times for each day. Smart medicine time indication box contains separate sub-boxes. Therefore, nurses or users can set information of these sub-boxes for different pills. When the pill quantity and time have been set, the medicine box will remind users or patients to take pills using sound and light. The specific number of pills needs to be taken will be displayed by a seven segment led display placed on the corresponding sub-box. Compared with the old-fashioned pill box that needs user or nurse to load the box every day or every week. This smart medicine time indication box would significantly reduce nurses or users' burden on frequently preloading pills for patients or users.
\end{abstract}

Keywords: Smart medicine time indication box, Pills, Microcontroller Atmega1284P and segment led display

\section{Introduction}

Now a days so many peoples always have trouble remember the number of pills they need to take from each of the medicine bottle because they couldn't read English [1]. They also complained to me that they sometimes forget to take to pills [2], and some medicines were expired due to this reason. Therefore, the idea to make a smart pillbox that would help people. Users of our pillbox from just the older to people who regularly take pills also nurses who take care of patients could also benefit since they also regularly prepare pills for patients. The device should be able to generate loud sound so that even people with impaired hearing were able to hear it. The device should demonstrate ease of use. Therefore, we use a LCD and a keypad as the user interface. In order to help user remember the number of pills they need to take, we also used several seven segment LED displays to indicate the number of pills the user need to take.

\section{Block Diagram}

There are five major components required for the design including a pill box containing some separate small boxes they are

1) Speaker module

2) Keypad

3) Atmel 1284p microcontroller

4) Seven segment display

5) LCD

The block diagram and functionality of each component is given below.

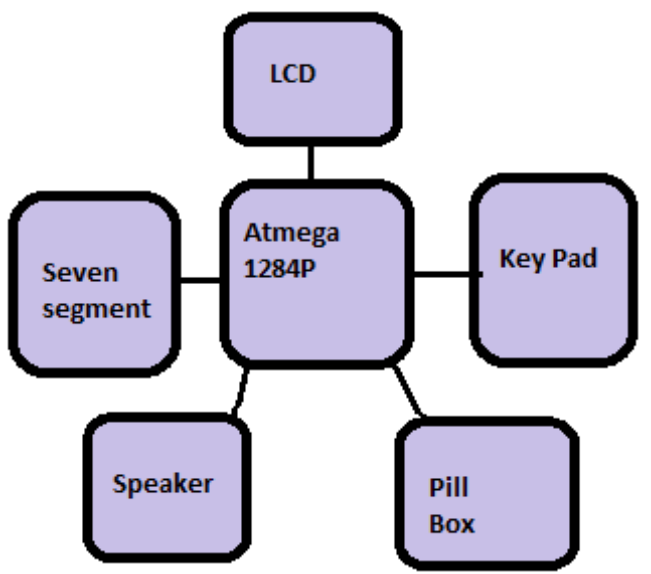

Figure 1: Block diagram for smart medicine time indication box

\subsection{Speaker Module}

The speaker module is used to play the synthesized sound to remind the user to take pill. We used a speaker module CDM-10008 from Digi Key. The output from the microcontroller was not large enough to drive it. Therefore, we used a sound amplification circuitry based on LM386 which amplify the sound from the microcontroller as shown in figure 2. After implementation of the audio amplification circuitry, we are able to generate a much louder sound from the speaker module.

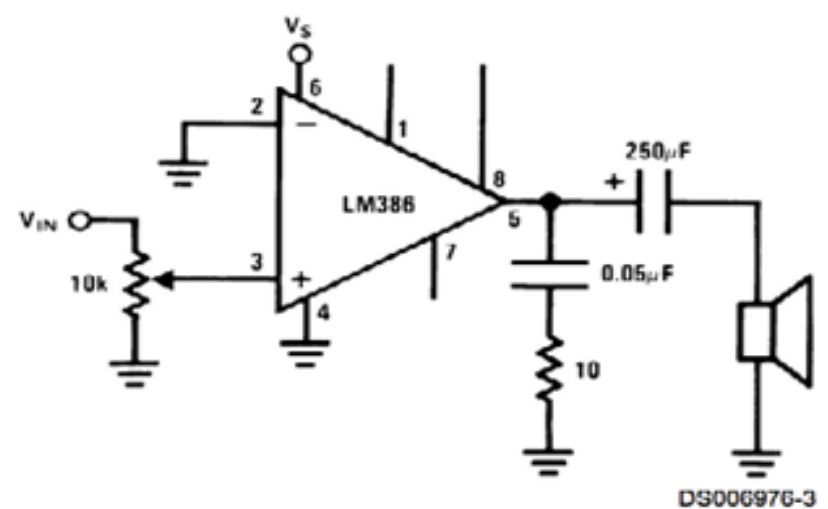

Figure 2: LM386 as a Sound Amplifier

Volume 6 Issue 1, January 2017 www.ijsr.net 


\section{International Journal of Science and Research (IJSR) \\ ISSN (Online): 2319-7064}

Index Copernicus Value (2015): 78.96 $\mid$ Impact Factor (2015): 6.391

The sound generation purpose differential pulse-code modulation (DPCM) method is used, for time generation purpose timer 0 is used, which is working at PWM mode and timer 2 working at compare match status in order to simulate the human speaking sound. We used the Matlab code to generate the sound data table of the sound we need that is 'Time to take medicine'.

\subsection{Keypad}

Keypad is used for the user or nurse to enter the information of time when the smart box would send "reminder" (displaying numbers and playing synthesized voice). A $3 \times 4$ 12 button keypad is used for the device. It is also used for the user to enter a number to command a specific pill box to open on a specific day. The keypad is also used for stopping the music and led display when the user has taken the pill.

A function for scanning the keypad by corresponding button that is pushed. Firstly, set high 4 bits input port and low-4 bits to output. Calculate the value of the high- 4 bits, then inversely do the same task and get the whole value of port. Then using this value we get to look up the button table to find out which button we pushed. The state machine will execute every 25 milliseconds. In state detect, we will judge which kind of button is pushed and do different things corresponding to the button, such as run flag setting, input string updating and changing to next parameter input.

\subsection{ATMEGA 1284P}

Atmel 1284p is used to do the tasks of all the devices which are connected. A medicine box with an integrated software system running in the Atmel 1284p. The programming platform is AVRStudio4.0, and programming language is standard C and WINAVR/GCC compiler. Generally, the software system can be divided into four parts including real time clock, user interface, LED control and sound generation. We could get information for each medicine boxes from the user input and store the information in structure variables. The real time clock would keep running once user finishes initialization. After all the information has been entered. The system would enter comparison status. The comparison function would detect if there are medicine should be taken at that time [3]. When it finds medicine should be taken, the audio will broadcast. After the user response to the system by pushing certain button, LEDs would indicate the amount of medicines for each box.

\subsection{Seven Segment Display}

Seven segment display is placed on the box. For the present pill system, the user can store up to seven different types of pills, which can be stored in those seven small separate boxes. He or she can also specify the different combinations of pill boxes [4] to be open for each day.

Port A is used for microcontroller to transfer the data for seven segments and first three bits of port B to transfer the control signal for the multiplexer. Hence, our function related to LED control is mainly controlling all this bits mentions above. Depends on the principle of persistence of vision, we will show the data of each LED for a short time and then switch to the next one, and doing this again and again to keep the LED lighting up. In the present system, the function called led () will execute this task according to the scheme mentions above. It will run every 4 milliseconds when the system running at triggered state.

\subsection{LCD}

The LCD module used in this project is a 16-characters, 2 lines Microtivity IM161 (with back light). Considering its small size, ease of use and its yellow back, we think it is the best candidate for our project. We found the yellow back light make it easier for the user to see the characters displayed on it, even in the dark environment. Pin 1 of the LCD module is connected to the ground. Pin2 is connected to the power supply of the MCU. Pin 3 connects to the wiper of the $10 \mathrm{k}$ trim pot. Pin 4 is the register select, which is connected to the C.0. Pin 5 is the data read/write, which is connected to C.1. Pin 6 is the enable signal, which is connected to C.2. Pin 11 to pin 14 are the data bus, which are connected to C.3-C.7. Pin15 and pin16 are the LED power and ground for the backlight. The optimal power and current for the led backlight is $4.2 \mathrm{~V}$ and $20 \mathrm{~mA}$.

\section{Results and Discussions}

The device's logic structure contains three major stages those are user initialization stage, Comparison stage and reminder stage. In the user initialization stage, the user enters the current time, date and pill information (including amount and serve time for each type of pill) [5]. After the user finishing entering all the information, the device will enter the comparison stage unless the initialization button is pressed. During the comparison stage, the system compares the pill information for each of the sub-box with the time counted by RTC. Once the information entered by the user matches the RTC time, the system will jump out of comparison stage and enter the reminder stage. In the reminder stage, the device will continuously play synthesized voice, and the seven segments LED display will show the number of pills needs to be taken on each of the sub-box. The total system is shown in the photograph 1 .

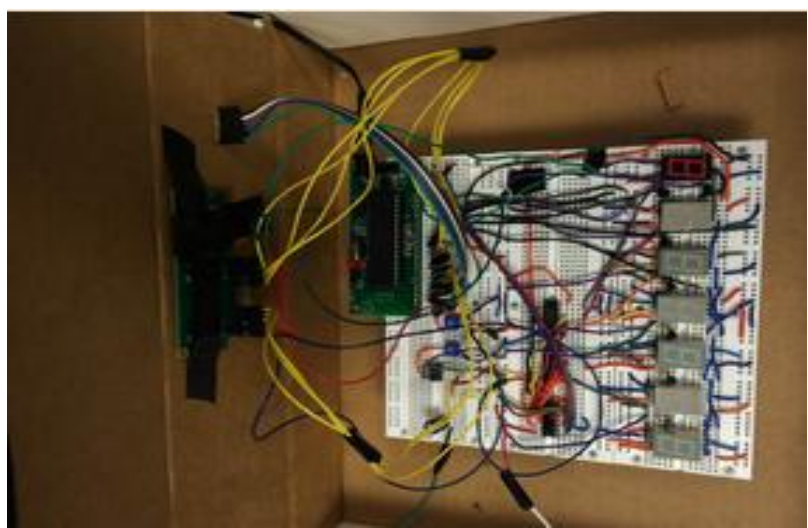

Photograph 1: Total system for smart medicine time indication box

The overall performance of our device was satisfied. The LCD module and keypad were mounted on the surface of the box. When the power is on, the LCD would display characters with the gentle yellow backlight, which allows the

Volume 6 Issue 1, January 2017 www.ijsr.net 
user to recognize the characters on the screen even in dark environment. With the implementation of state machine, the keypad responded promptly and accurately when we pressed the buttons. The long press and backspace features went well during the initialization stage. The seven units of seven segment led displays were placed inside the box since they were embedded on the breadboard. During the test, we found that the light intensity for some led displays was a little different than the others, but this would not affect the users to recognize the numbers displayed. The speaker was able to produce clear and loud sound when the comparison stage was triggered. When the "\#" key was pressed, the sound stopped, and we were able to see led displays show corresponding numbers without any flicker.

\section{References}

[1] Wandless I, Mucklow JC, Smith A, and Prudham D Improving oral medication compliance with an electronic aid Engineering in Medicine and Biology Magazine, IEEE

[2] www.epill.com/smartpillbox.html

[3] http://www.pivotell.co.uk/how-the-Pivotellworks.Atmel/mega1284full.pdf

[4] smart pill box, Aakash Sunil Salgia*, K. Ganesan and Ashwin Raghunath Indian Journal of Science and Technology, Vol 8(S2), 189-194, January 2015, ISSN (Online) 0974-5645.

[5] Russel,S.,Norvig,P. (2013). Artificial Intelligence: A Modern Approach (3rd ed.). Prentice Hall

\section{Author Profile}

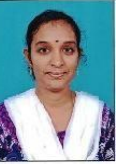

Dr. U. Suneetha is working as Teaching Assistant in the Department of Electronics Sri Krishna devaraya university, Anantapur. She is having thirteen years of teaching experience. Her area of interest are Wireless communications, analog and digital system design and Embedded systems. She has produced more than 10 research papers in national and international journals. 